\title{
Early Identification and Incidence of Mild TBI in Ontario
}

\author{
Won Hyung A. Ryu, Anthony Feinstein, Angela Colantonio, David L. Streiner, \\ Deirdre R. Dawson
}

\begin{abstract}
Objectives: (1) To examine the variability in diagnosis of mild traumatic brain injury (mTBI) in primary care relative to that of an expert reviewer; and (2) to determine the incidence rate of mTBI in Ontario, Canada. Method: Potential mTBI cases were identified through reviewing three months of Emergency Department (ED) and Family Physician (FP) health records. Potential cases were selected from ED records using the International Classification of Disease, 9th revision, Clinical Modification and External Cause codes and from all FPs records for the time period. Documented diagnoses of mTBI were compared to expert reviewer diagnosis. Incidence of mTBI was determined using the documented diagnoses and data from hospital catchment areas and population census. Results: 876 potential mTBI cases were identified, 25 from FP records. Key indicators of mTBI were missing on many records (e.g., 308/876 records had Glasgow Coma Scale (GCS) scores). The expert reviewer disagreed with the documented diagnosis in $380 / 876$ cases (kappa=0.19). The expert reviewer was more likely to give a diagnosis if the GCS was 13-14, if there was documented loss of consciousness and/or post-traumatic amnesia, and/or if there was pathology found on an acute brain scan. Calculated incidence rates of hospital-treated mTBI were 426 or 535/100,000 (expert review - hospital diagnosis). Including family physician cases increased the rate to 493 or 653/100,000. Conclusion: Health record documentation of key indicators for mTBI is often lacking. Notwithstanding, some patients with mTBI appear to be missed or misdiagnosed by primary care physicians. A more comprehensive case definition resulted in estimated incidence rates higher than previous reports.
\end{abstract}

RÉSUMÉ: Identification précoce et incidence du traumatisme cérébral léger en Ontario. Objectifs : (1) Examiner la variabilité dans le diagnostic du traumatisme cérébral léger (TCL) en première ligne par rapport au diagnostic d'un réviseur expert et (2) déterminer le taux d'incidence du TCL en Ontario, Canada. Méthode : Nous avons identifié les cas potentiels de TCL par révision des dossiers du service des urgences et des médecins de famille sur une période de trois mois. Les cas potentiels identifiés à partir des dossiers du service des urgences au moyen de la Classification internationale des maladies, 9e révision, modification clinique et codes des causes externes, et de tous les dossiers des médecins de famille pour ces trois mois. Les diagnostics de TCL certains selon les dossiers ont été comparés aux diagnostics de l'expert réviseur pour ces mêmes cas. L'incidence de TCL a été déterminée d'une part au moyen des diagnostics certains et des données hospitalières des secteurs sanitaires et d'autre part du recensement de population. Résultats : Huit cent soixante-seize cas potentiels de TCL ont été identifiés dont 25 à partir des dossiers des médecins de famille. Des indicateurs clés d'un TCL étaient absents de plusieurs dossiers (par exemple 308/876 dossiers contenaient un score du Glasgow Coma Scale (GCS)). Le réviseur expert était en désaccord avec le diagnostic établi chez 380/876 cas (kappa =0,19). Le réviseur expert était plus enclin à poser ce diagnostic si le score GCS était de 13 ou 14, si le patient avait perdu conscience et/ou avait présenté une amnésie post-traumatique et/ou si le scan cérébral effectué en phase aiguë était pathologique. Les taux d'incidence calculés pour les cas de TCL traités à l'hôpital étaient de 426 ou 535/100,000 (révision par l'expert - diagnostics hospitaliers). Si on inclut les cas des médecins de famille, le taux passait à 493 ou 653/100,000. Conclusion : Les indicateurs clés de TCL sont souvent absents des dossiers médicaux. Néanmoins, il semble que le diagnostic de TCL soit manqué ou qu'un diagnostic erroné soit posé par le médecin de première ligne. Une définition de cas plus complète a fourni des taux d'incidence estimés plus élevés que ceux rapportés antérieurement.

Can. J. Neurol. Sci. 2009; 36: 429-435

Mild traumatic brain injury (mTBI) accounts for 70 to $90 \%$ of all TBI cases and is a major source of morbidity with up to 15 to $20 \%$ of patients experiencing long-term complaints ${ }^{1-5}$. Surprisingly, early detection of mTBI continues to be a considerable challenge. There is a discrepancy between the emphasis on acute injury characteristics such as post-traumatic amnesia (PTA) in the definitions found in mTBI literature, and the operational definitions of mTBI used in clinical settings ${ }^{6-9}$. Surveys of European hospitals and US Level I trauma centres found that there was little agreement in how mTBI was diagnosed $^{9-11}$. Specifically, only $46 \%$ of the US Level I trauma centres reported using a formal evaluation for all diagnosed
mTBI patients while $17 \%$ did not evaluate any mTBI patients ${ }^{10}$. Furthermore, the reported methods of evaluating patients for

From the Kunin-Lunenfeld Applied Research Unit (WHAR, DLS, DRD), Baycrest; Graduate Department of Rehabilitation Science (WHAR, AC, DLS, DRD), Departments of Occupational Science \& Occupational Therapy (AC, DRD) and Psychiatry (AF, DLS), University of Toronto; Toronto Rehabilitation Institute (WHAR, AC, DRD); Sunnybrook Health Sciences Centre (AF), Toronto, Ontario, Canada. Received December 8, 2008. Final Revisions Submitted February 9, 2009. Correspondence to: Deirdre Dawson, Kunin-Lunenfeld Applied Research Unit, Baycrest, 3560 Bathurst St., Toronto, Ontario, M6A 2E1, Canada. 
mTBI varied from recording self-reported symptoms, to using specific standardized tests (e.g. Galveston Orientation and Amnesia Test, Wechsler Memory test, Brain Injury Test Battery) or a combination of both ${ }^{10}$. Similarly, over $47 \%$ of leading neurosurgeons in Germany responding to a survey of diagnosis and management of mTBI by the European Federation of Neurological Societies reported that guidelines for managing mild brain injury were not available in their country ${ }^{12}$. Among the same group, only $20 \%$ indicated there were no guidelines at their particular hospital suggesting that many had developed sitespecific guidelines - a potential source of the discrepancy in operational definitions.

In the acute management phase accurate diagnosis of patients with potential brain injury allows classification of the brain injury based on severity which in turn assists in determining patients' prognoses and guides the application of assessment tools (e.g., computed tomography scans) to identify intracranial lesions requiring immediate medical care ${ }^{13}$. The acute diagnostic procedure for patients with suspected brain injury should begin with a clinical evaluation focusing on level of consciousness, amnesia, physical and neurological examination ${ }^{14}$. Findings will aid in determining whether more advanced diagnostic tests, such as computed tomography (CT) scans and magnetic resonance imaging are necessary ${ }^{13}$. However, some patients with mTBI may be ill-served on first entry to the health care system due to the inconsistencies in practice procedures. The major clinical implication of this is that mTBI patients may be undiagnosed (missed) or that patients without mTBI may be given that diagnosis (misdiagnosed). Along the health care continuum, it is likely that some of these patients then receive conflicting diagnoses by neurologist, neurosurgeons, neuro-psychologists, and psychiatrists who are using different definitions of mTBI. Given that simple early patient education has been shown to reduce long-term complaints following mTBI, the value of accurately identifying mTBI cases is clear ${ }^{15,16}$.

Variability in diagnoses also creates major challenges for determining the incidence rate of mTBI. First is the well-known difficulty in defining and selecting mTBI cases ${ }^{17}$. Kraus et al (1994) stated that "even among the most detailed of epidemiologic studies in brain injury, the definition of a case and the criteria for and scoring of injury severity have varied markedly." 18 . Second is the challenge of identifying the various primary care settings that mTBI patients may visit. For example, in rural areas or areas where hospital access is difficult, mTBI patients may prefer visiting family physician clinics. Therefore, relying on one source of data (e.g. hospital records) may lead to underestimation of the incidence rate. Moreover, given that only $45 \%$ of potential brain injury cases in Ontario were hospitalized, the admission and discharge records may only highlight more serious injuries ${ }^{19}$. It is important to keep in mind that incorporating different types of primary care settings in epidemiological studies still will not account for the up to $25 \%$ of mild to moderately brain injured individuals who do not seek any medical care ${ }^{20,21}$.

Thus, the objectives of this study were: 1) to further our understanding of the variability in acute diagnostic procedure for potential mTBI in the primary care settings (defined as the patient's first point of entry into the health care system, specifically ED and FP clinics ${ }^{22}$ ) by determining whether patients with mTBI are being missed and/or misdiagnosed through comparison of primary care physician diagnosis to that of a expert reviewer; and 2) To determine the incidence rate of mTBI in Ontario, Canada based on emergency department and family physician records.

\section{MethodS \\ Design}

This study used a retrospective cross-sectional design.

\section{Sample}

Three months of records (within November to February) were reviewed in 2001 from 12 EDs and 19 FP clinics selected from the five different geographical regions in Ontario designated by the Ontario Hospital Association (OHA) and to include urban (defined as metropolitan areas with a population of at least $100,000^{23}$ ) and rural, teaching, and non-teaching centres. Each participating hospital provided ethics approval for the study as did the University of Toronto and Baycrest Research Ethics Boards. Twelve of 14 hospitals and 19 of 76 FPs agreed to participate. The most common reason FPs reported for not participating in the study was lack of time.

In order to obtain records of as many people with mTBI as possible whether or not they had a documented diagnosis on their health record we used the following methods. For ED data, health records departments were asked to pull three consecutive months of ED records using the International Classification of Disease, 9th revision, Clinical Modification (CM) codes specifying for potential brain injury and the External Cause for Injury codes (E-codes) for any injuries involving acceleration/ deceleration including motor vehicle crashes, accidental falls, other accidents, late effects of accidents and assault ${ }^{24}$. The specific ICD-9-CM codes used included those for either fracture of skull or intracranial injury (ICD-9-CM 800-804; 850-854). Thus, records were pulled for potential mTBI cases. We hypothesized that not everyone who actually had an mTBI would have a documented diagnosis of mTBI and be given the correct CM code. In the case of the FPs, the case extraction involved reviewing physician's notes of all patients seen in a three-month period. Patients were categorized as potential mTBI cases if they had received one or more of the following: (1) a diagnosis on their health record of concussion or mild brain injury; (2) Glasgow Coma Scale (GCS) scores of 13 or 14; (3) head trauma involving acceleration/deceleration; (4) if they were prescribed to receive head injury routine (e.g., being awakened every one to two hours to look for any changes in symptoms $)^{10}$; (5) any loss of consciousness (LOC), (6) any loss of memory for events immediately before or after the accident (known as posttraumatic amnesia); (7) any alteration in mental state at the time of the accident (e.g. feeling dazed, disoriented, or confused), and/or (8) focal neurological deficit(s) that may or may not be transient (9). If there was no diagnosis of TBI on the health record, patients were excluded as potential mTBI cases if they had; 1) only injuries not involving the head and/or 2) severe brain injury marked by LOC $>30$ minutes, GCS $<13$, and/or PTA $>24$ hours $^{7}$. Patients under 16 years-of-age were also excluded. In order to prevent double counting of potential mTBI patients, only patients visiting the participating EDs or FP clinics 
as their first point of contact into the health care system were included. Each potential mTBI case identified in the FP records was checked to ensure that the person had not previously received acute care for their injury and those visiting the ED or FP for follow-up care were excluded. This procedure resulted in 876 records of people with a potential (or possible) mTBI, a subset of which has a documented diagnosis.

\section{Procedure}

Trained research assistants visited each participating ED and FP in pairs to undertake record extraction. Over 21,000 patient records from the 12 EDs and over 23,000 patient records from 19 FP clinics were reviewed. Data extracted from the health record of each potential mTBI patient included (where ever possible): age, gender, mechanism of injury, presence and length of loss of consciousness or/and post-traumatic amnesia, GCS scores, blood alcohol levels, symptoms potentially related to brain injuries (headache, nausea, vomiting), computed tomography scan results, head/neck examination results, neurological examination results, and management orders that specified head injury routine. Other factors recorded were mode of arrival at hospital, and type of primary care setting (ED vs. FP; rural vs. urban centres; teaching vs. non-teaching centres).

In order to address the issue of missed and/or misdiagnosed mTBI cases, a review of the extracted data of the 876 potential mTBI cases was performed by a physician experienced in diagnosis and management of TBI as this physician is the director of a large brain injury clinic. This was our 'expert' reviewer. This reviewer typically uses the American Congress of Rehabilitation Medicine's definition of mTBI as the primary guide for diagnosis along with considering supplemental information extracted from the patient charts (e.g. symptoms, examination data, CT scan results, medical history, blood alcohol level, etc.). We elected to use an expert for this second review as this physician is highly experienced at evaluating brain injury, its complications, and undertaking differential diagnosis in the presence of conflicting information.

\section{Data Analyses}

Diagnostic Variability: Descriptive statistics were carried out to characterize the sample of potential mTBI patients and to compare patients who had a documented (i.e., in the health record) diagnosis of mTBI from their primary care physician with those who did not have a diagnosis of mTBI in their health record. To address objective one regarding variability in diagnosis of mTBI, we investigated: (1) whether, among all potential mTBI patients, there were significant differences on patient and injury related characteristics as well as in relation to the type of primary care at which they were first seen (ED vs. FP) between the patients with a documented diagnosis of mTBI and those without. Pearson chi-square tests for nominal data and Mann-Whitney $U$ tests for continuous data were used ${ }^{25}$; and (2) the level of agreement in diagnosis between the primary care physicians and the expert reviewer by using Cohen's Kappa ${ }^{26}$. Although Cohen's Kappa is not designed to be used between multiple reviewers, it is the best statistic available to provide us with this kind of approximation. Mechanism of injury was not included in the comparative analyses because the magnitude of acceleration/deceleration associated with the injury was not included in the patient charts. All analyses were conducted using Statistical Package for the Social Sciences 15.0 Software (SPSS 15.0) for Windows.

Incidence of $m T B I$ : Incidence rates for $\mathrm{mTBI}$ in the province of Ontario were calculated based on the primary care physicians' acute diagnosis and on the expert reviewer's diagnosis. The numerator in both instances was calculated based on the data obtained from participating EDs considering their specific catchment areas. The denominator for these calculations was all persons over 16 years-of-age living in Ontario, Canada at the time of data collection (obtained from 2001 Statistics Canada Census) ${ }^{23}$. The number of cases from three months of ED records was extrapolated to one year and subsequently weighted based on the relative population of the catchment area to their corresponding OHA region. Thus, the incidence rate equation used was; Rate $=[\#$ case $/ y r \mathrm{x}$ weighting of catchment area $] \mathrm{x}$ [100,000/total population]. For example, if a hospital in Ottawa (with a catchment population of 500,000 and OHA region population of 1.8 million; catchment area weighting of 3.6) recorded 400 cases of mTBI in one year, the annual incidence would be $80 / 100,000$. The data from three months of FP clinic records was extrapolated to one year and subsequently to the number of FPs practicing during the year of data collection in 2001. The number of active FPs was retrieved from the Ontario Physician Human Resources Data Centre - a source of physician information practicing in Ontario ${ }^{27}$.

\section{Results}

\section{Diagnostic Variability}

From the review of patients' health records, 876 cases were identified as potentially having a mTBI (851 from EDs and 25 from FP clinics). These included 509 patients who had a documented diagnosis of mTBI on their health record. That is, these patients were given this diagnosis by their primary care physician. An additional 367 patients did not have a documented diagnosis. A comparison of these two groups on variables that would normally contribute to the diagnosis of mTBI is shown in Table 1. Of note, is that relatively few health records had documentation of a number of the critical variables used to determine whether or not someone has an mTBI. For example, only 308/876 (35.2\%) records included GCS scores. The length of loss of consciousness and/or presence or absence of posttraumatic amnesia were most commonly documented (727/876 records $-83 \%$ ). Surprisingly, the proportion of people with a GCS score of 13 or 14 with a documented diagnosis of mTBI was no different than that given no diagnosis. Similarly there was no statistically significant difference in the proportion of people with documented LOC and/or PTA given an mTBI diagnosis compared to that not given a diagnosis. Further, significantly fewer patients with abnormal findings on acute brain CT scans (i.e., new contusions, subdural hemorrhages, intra-cranial bleeds) were diagnosed with TBI than expected. As would be expected significantly more patients with headaches, nausea and/or vomiting were given a diagnosis of mTBI and significantly more patients prescribed a head injury routine as follow-up were given a diagnosis of mTBI although notably 117 patients not diagnosed with mTBI were prescribed a head injury 
Table 1: Comparison of patients with a documented mTBI diagnosis and those without

\begin{tabular}{|c|c|c|c|}
\hline Patient Characteristics & $\begin{array}{l}\text { Overall } \\
(\mathrm{n}=876)\end{array}$ & $\begin{array}{c}\underset{(\mathrm{n}=509)}{\mathbf{m T B I}} \mathbf{D X} \\
\end{array}$ & $\begin{array}{l}\text { No mTBI DX } \\
\quad(\mathrm{n}=367)\end{array}$ \\
\hline \multicolumn{4}{|l|}{ Demographic Data } \\
\hline - Mean Age \pm SD & & $41.2 \pm 20.9$ & $42.2 \pm 21.0 *$ \\
\hline - Gender - male & $486 / 876 \ddagger$ & 295 & 191 \\
\hline \multicolumn{4}{|l|}{ Documented Injury-Related Data } \\
\hline - GCS of $13-14$ & $61 / 308$ & 37 & 24 \\
\hline - LOC/PTA & $232 / 727$ & 154 & 78 \\
\hline - Brain pathology on acute CT scan & $27 / 180$ & 14 & $13^{*}$ \\
\hline - Headache & $390 / 498$ & 225 & $165^{*}$ \\
\hline - Nausea & $151 / 362$ & 109 & 42 \\
\hline - Vomiting & 54 / 363 & 41 & 13 \\
\hline - Confusion & $65 / 85$ & 47 & 18 \\
\hline - Cognitive deficit & $30 / 46$ & 17 & 13 \\
\hline - Balance problem & $21 / 35$ & 15 & 6 \\
\hline - Abnormal Neurological exam & $50 / 689$ & 31 & 19 \\
\hline - Head Injury routine & $333 / 333$ & 216 & $117 * *$ \\
\hline \multicolumn{4}{|l|}{ Primary Care Characteristics } \\
\hline - Visited ED first & $851 / 876$ & 502 & 349 \\
\hline - Visited Urban centre & $515 / 851$ & 327 & 188 \\
\hline - Visited Teaching hospital & 143 / 851 & 106 & 37 \\
\hline - Arrival by ambulance & $232 / 851$ & 134 & $98^{*}$ \\
\hline - Visited FP first & $25 / 876$ & & \\
\hline
\end{tabular}

$\ddagger$ Denominator represents the total number of cases for which the variable was documented; ${ }^{*} \mathrm{p} \leq 0.05 ; * * \mathrm{p} \leq 0.01$

routine for follow-up.

The level of agreement on diagnosis between the expert reviewer and the diagnosis provided in primary care was very low (Table 2). Of the 876 potential mTBI cases, there was agreement on only 516 cases $(59.5 \%)(\mathrm{k}=0.19, \mathrm{CI}=0.1-0.3)$. Of the 360 discrepant cases, 236 were given a diagnosis of mTBI by a primary care physician but not by the expert reviewer whereas 124 were given a diagnosis of mTBI by the expert reviewer but not by the primary care physician. The lack of documentation in the health records precluded an in-depth analysis of all discrepancies. For example, only 122 of the discrepant cases had documented GCS scores. Notably, 20 people with a documented GCS of 13-14 did not have a documented diagnosis of mTBI on their health records whereas 69 people with a documented GCS of 15 did. Of the two cases with a documented GCS of 13-14 not given a diagnosis of mTBI by the expert reviewer, one had fallen after coming out a pub and had a high blood alcohol level; the other had a secondary diagnosis of dementia. Of the 20 given an mTBI diagnosis by the expert reviewer but not by the ER, ten also had a documented LOC and ten had a documented PTA but none of these had a documented mTBI. Indeed, a total of 64 people with documented LOC and/or PTA were not given a diagnosis of mTBI in primary care. Perhaps most surprising is that 11 of the 12 discrepant cases with abnormal brain pathology on acute scan were not given a diagnosis of mTBI. The person with abnormal brain pathology not given a diagnosis of mTBI had a GCS of 11 and was given a diagnosis of moderate TBI. In sum, the expert reviewer diagnosed more patients as mTBI if they had GCS scores of 13-14, documented LOC and/or PTA, intracranial complications, nausea, vomiting, and abnormal neurological exam results.

\section{Incidence of mTBI}

Incidence rate estimates are reported in Table 3. Two rates were calculated, one based on the diagnoses provided by the primary care physicians, the other on the expert review diagnosis. In both instances, the denominator for the rates was the total adult population (age 16+) in Ontario in 2001 which was 9.4 million. The numerator for incidence rates for ED cases was calculated as described in the planned analyses by weighting the population of the ED catchment area to the corresponding OHA region. The population of the $12 \mathrm{ED}$ catchment areas in 2001 was approximately 1.4 million. Thus, for the ED cases alone, the incidence rate calculated was between 426 (as per expert reviewer) and 535 (as per ED physician).

The numerator for the FP incidence rates was extrapolated given that in 2001, the total number of active FPs in Ontario was 9,478. From the 19 participating FP clinics, nine FPs had potential mTBI cases in the three months of patient records. Of the 25 potential mTBI cases identified through FP records, seven 
Table 2: Documented mTBI criteria for cases provided with discrepant diagnosis by reviewers $(n=360)$

\begin{tabular}{lccccc}
\hline & & $\begin{array}{c}\text { Health } \\
\text { Record } \\
\text { Diagnosis }\end{array}$ & $\begin{array}{c}\text { Secondary } \\
\text { Review } \\
\text { Diagnosis }\end{array}$ & k & 95\% CI \\
$\begin{array}{l}\text { Total Number of Cases } \\
\text { Injury-related Data* }\end{array}$ & 236 & 124 & 0.19 & $0.1-0.3$ \\
- Documented GCS 13-14 & $(\mathrm{n}=22)$ & 2 & 20 & 0.13 & $-0.2-0.4$ \\
- Documented GCS 15 & $(\mathrm{n}=100)$ & 69 & 31 & 0.19 & $0.1-0.3$ \\
- Documented LOC/PTA & $(\mathrm{n}=90)$ & 26 & 64 & 0.01 & $-0.1-0.2$ \\
- No documented LOC/PTA & $(\mathrm{n}=206)$ & 163 & 43 & 0.20 & $0.1-0.3$ \\
- Documented Head Pathology & $(\mathrm{n}=12)$ & 1 & 11 & 0.09 & $-0.3-0.5$ \\
- Documented Headache & $(\mathrm{n}=133)$ & 70 & 63 & 0.31 & $0.2-0.4$ \\
- Documented Nausea & $(\mathrm{n}=41)$ & 17 & 24 & 0.29 & $0.1-0.5$ \\
- Documented Vomiting & $(\mathrm{n}=20)$ & 7 & 13 & -.04 & $-0.4-0.3$ \\
- Abnormal Neuro Exam & $(\mathrm{n}=24)$ & 11 & 13 & -.04 & $-0.3-0.3$ \\
\hline
\end{tabular}

*The number of cases for which the variable was available is shown

patients were diagnosed as mTBI by the primary care physicians and four were diagnosed as mTBI by the expert reviewer. Of particular note, approximately $18 \%$ of total mTBI incidence rate was identified from FP records.

\section{Discussion}

This study is the first to investigate the variability in diagnostic criteria for mTBI in Ontario and indeed in Canada and the first to provide estimates of mTBI incidence that include cases presenting first to family physician offices. Our results suggest that mTBI incidence estimates may be under reported for two reasons. First, it appears that there are a substantive number of people being misdiagnosed with mTBI based on our analyses. Secondly, a considerable portion of patients with mTBI present first to family physician offices rather than EDs. These cases have not been included before in incidence rates. Clinically, the missing documented (or simply missing) and misdiagnosed cases of mTBI may result in increased difficulty for patients. Those who do have an mTBI but do not receive a diagnosis may not receive interventions that in some instances could be helpful ${ }^{28,29}$. Early intervention is particularly important in patients with pre-injury psychiatric problems in preventing longterm complaints ${ }^{28}$. Conversely patients who receive the diagnosis of mTBI without actually having one may be subject to unnecessary worry and stress. Finally, as Russell argued in his seminal paper, making the diagnosis is important because it is predictive of what comes next ${ }^{30}$.

\section{Diagnostic Variability}

Our data suggest that mTBI is both missed and misdiagnosed in the primary care setting (ED and FP offices). One possible explanation for missed diagnoses is a lack of accurate documentation. That is, physicians are making the correct diagnosis but this is not being documented on the health record. Given the busyness of emergency departments it is entirely feasible that all relevant information is not recorded. Our data suggest this as there are many records missing data relevant to the TBI diagnosis such as GCS scores and loss of consciousness. However, it may also be the case that physicians are not recognizing mTBIs. This would account for missed and misdiagnosis and is a problem that has been identified in other populations as well. For example, Hustey and Meldon reported

Table 3: Incidence rate estimates of $\mathrm{mTBI}$ in Ontario

\begin{tabular}{lccc}
\hline & ED & FP & Total \\
Dx by Primary Care Physicians & $535 / 100,000$ & $118 / 100,000$ & $653 / 100,000$ \\
Dx by Secondary Reviewer & $426 / 100,000$ & $67 / 100,000$ & $493 / 100,000$
\end{tabular}


that only $22 \%$ of elderly patients seen in an ED and known to have mental status impairment had documentation attesting to this $^{31}$. Hustey and Meldon suggest that the cause of this was that ED physicians failed to recognize this problem. The same could be true in the case of mTBI, a diagnosis of some controversy ${ }^{3}$ and complicated by the fact that there is no diagnostic gold standard $^{3,9,13,32}$ although recommendations do exist. For example, Kennedy noted that physicians should consider acute indicators of clinical deterioration (i.e. GCS score $<15$, LOC, PTA, vomiting, neurological deficits) during their acute evaluation of mTBI patients ${ }^{14}$. A failure of recognition would also at least in part explain misdiagnosis as well. A third reason is that the definition used by our expert reviewer is different than that used in many acute care settings.

Lack of documentation and lack of knowledge are two possible reasons for our findings. Interestingly, there seemed to be some systematic bias associated with this. The number of patients diagnosed with mTBI by primary care physicians was significantly different based on the type of primary care settings. Patients were more likely to receive this diagnosis if they presented to EDs versus FPs, to teaching versus non-teaching hospitals and to urban versus rural settings. We were not able to determine the reason for this bias but it may be that urban, teaching affiliated EDs have more resources that would allow more attention to be paid to diagnosis and documentation.

It would be remiss not to discuss the possibility that it is likely that some missed and misdiagnosed cases may be related to a lack of knowledge regarding mTBI. We suggest this as a number of patients with key indicators of brain injury (i.e., GCS 13 to 14, LOC and/or PTA, intracranial complications) did not receive a diagnosis of mTBI whereas other patients were given a diagnosis without any key indicators (e.g., GCS=15, no LOC, no PTA). Given the increasing awareness about the possible deleterious effects of even very mild $\mathrm{TBI}^{5}$, it would seem important to find ways to disseminate knowledge about diagnosis of mTBI to physicians in ways that can be readily utilized. Such tools are widely available for decisions about return to play in sports (e.g., Sports Concussion Assessment Tool card and Practice Parameter: The Management of Concussion in Sports ${ }^{9,33}$.

\section{Incidence of mTBI}

To the best of our knowledge, we are the first to attempt to count cases of mTBI that present first in family practitioners offices. Our hospital-treated rate was $535 / 100,000$ based on documented cases of mTBI and 426/100,000 based on the expert review of data extracted from charts. These rates increased to $653 / 100,000$ and 453/100,000 respectively when cases seen in family physician offices were included. Although our sample was small, the $18 \%$ increase in incidence attributable to non hospital-treated cases is startling but does fit with previous estimates. Cassidy ${ }^{1}$ reported that published incidence rates of hospital-treated cases with mTBI range from 100 to 300/ 100,000 population but that true rates (including those not treated in hospital) was probably above 600/100,000. The distribution of the mTBI patient population visiting the different primary care settings (ED vs. FP) as their entry into the health care system is similar to the findings from US studies on TBI that reported approximately 15 to $31 \%$ of TBI patients visited an outpatient clinic or physician's office ${ }^{20,21}$. Our data confirm the hypothesis in the literature that using only the hospital records results in an inaccurate underestimation ${ }^{1}$.

Our hospital-treated rates of mTBI were higher than those reported in the review paper by Cassidy ${ }^{1}$. The most likely reason for this is the way we selected cases. Many epidemiological studies of mTBI defined cases based only on the ICD-CM codes $^{1}$. Additionally, in a number of studies, cases of mTBI were identified by GCS scores. As seen in our data, these scores are missing in a large number of cases. Further, some studies excluded cases seen in the ED and only counted cases admitted to hospital. No studies have previously reviewed records identified by E-codes. We hypothesize that our estimate is closer to the real number of mTBI cases.

There are three important caveats to consider in our incidence calculation. A limitation in the interpretation and the generalizability of this study is the representativeness of the data. Our funding allowed us to collect data from only 12 EDs of 170 in Ontario and 19 FP clinics of the approximately 9,500 practicing FPs in the province. Nevertheless, these centres were strategically selected from each of five different geographic regions within Ontario as designated by the Ontario Hospital Association, and to include urban and rural centres as well as teaching and non-teaching facilities. We have no reason to believe that the patient population at these participating sites would be different from the other sites. Furthermore, while only a small fraction of the active FPs in Ontario participated in the study, this is the first study to include patients who sought acute care in FP clinics over hospital EDs. Given that an estimated $31 \%$ of patients visited physician offices instead of the hospital for head injury in the US, including the FP records in our study is a significant step towards improving our understanding of the epidemiology of $\mathrm{mTBI}^{20}$. Finally, it should be noted that our incidence estimate is likely conservative as we collected data in the winter months (November through February). Some epidemiological studies have found that December and January have lower injury rates than other months ${ }^{34}$.

The second limitation derives from accuracy of the ICD-9CM codes in identifying mTBI cases. Using the ICD codes for case ascertainment can lead to varying incidence rates depending on how these codes are assigned. For example, Tate et al reported that $77 \%$ of mTBI cases were not classified as concussion, while $43 \%$ of moderate to severe TBI cases were coded as concussion $^{35}$. Since a significant number of mTBI cases selected by the ICD codes are confirmed to be inaccurate, reports in the literature suggest caution in using the ICD codes as the only method of case ascertainment ${ }^{36,37}$. In effort to ensure more inclusive case ascertainment, we included all injuries that involve sudden acceleration/deceleration using the E-codes and ICD-9 codes.

Thirdly, the comprehensiveness of patient charts regarding the injury related information was a challenge for the expert physician review. Specifically, there were cases that the expert physician was uncertain of whether the patients had mTBI or not. The reasons for uncertainty included lack of data and the presence of confounding symptoms (e.g., seizure, syncope, dementia, intoxication). He noted during his review that not actually seeing patients hampered his ability to make a diagnosis.

Finally, our data are limited for some of the same reasons as others: there are additional cases of mTBI that do not go to either EDs or FPs (e.g., sports concussions), there are likely cases that 
did go to the EDs but were not captured in our sampling, and we did not review cases of moderate and severe TBI that may have been misdiagnosed as such.

In conclusion, the current incidence estimates of mTBI may be an under estimation of the actual incidence rate. Specifically, this may be due to poor documentation of key health information, inconsistent diagnostic procedure for potential mTBI cases leading to misdiagnosis, temporal variation in injury rates and failure to account for the various primary care settings that mTBI patients receive their initial diagnosis (ED and FP clinics). A possible clinical implication of missed cases or misdiagnosis is inadequate early management that could result in preventable long-term complaints.

\section{FUNDING}

Ontario Neurotrauma Foundation

\section{REFERENCES}

1. Cassidy JD, Carroll LJ, Peloso PM, Borg J, von Holst H, Holm L, et al. Incidence, risk factors and prevention of mild traumatic brain injury: results of the WHO collaborating centre task force on mild traumatic brain injury. J Rehabil Med. 2004 Feb; 43 Suppl:28-60.

2. Kurtzke JF, Kurland LT. The epidemiology of neurologic disease. In: Joynt RJ, editor. Clinc Neurol. Philadelphia: J.B. Lippincott; 1993.

3. Alexander MP. Mild traumatic brain injury: pathophysiology, natural history, and clinical management. Neurology. $1995 \mathrm{Jul}$; 45(7):1253-60

4. Rutherford WH, Merrett JD, McDonald JR. Symptoms at one year following concussion from minor head injuries. Injury. 1979 Feb;10(3):225-30.

5. Vanderploeg RD, Curtiss G, Luis CA, Salazar AM. Long-term morbidities following self-reported mild traumatic brain injury. $\mathrm{J}$ Clin Exp Neuropsychol. 2007 Aug;29(6):585-98.

6. Diagnostic and statistical manual of mental disorders: DSM-IV-TR. 4th ed. Text Revision. ED. American Psychiatric Association. and American Psychiatric Association, editors. Washington, DC: American Psychiatric Association; 2000.

7. Mild Traumatic Brain Injury Committee of the Head Injury Interdisciplinary Special Interest Group of the American Congress of Rehabilitation Medicine. Definition of mild traumatic brain injury. J Head Trauma Rehabil. 1993; 8(3):86-7.

8. Mild Traumatic Brain Injury Work Group. The report to Congress on mild traumatic brain injury in the United States: Steps to prevent a serious public health problem. National Center for Injury Prevention and Control; 2003. Report No.: 1.

9. Quality Standards Subcommittee of the American Academy of Neurology. Practice Parameter: The management of Concussion in Sports. [Cited January 2009] Available from: http://www.aan.com/professionals/practice/guidelines/pda/Conc ussion_sports.pdf.

10. Blostein $\overline{\mathrm{P}}$, Jones SJ. Identification and evaluation of patients with mild traumatic brain injury: Results of a national survey of level I trauma centers. J Trauma. 2003 Sep;55(3):450-3.

11. De Kruijk JR, Twijnstra A, Meerhoff S, Leffers P. Management of mild traumatic brain injury: lack of consensus in Europe. Brain Inj. $2001 \mathrm{Feb} ; 15(2): 117-23$

12. von Wild K, Terwey S. Diagnostic confusion in mild traumatic brain injury (MTBI). Lessons from clinical practice and EFNS-inquiry. European Federation of Neurological Societies. Brain Inj. 2001 Mar;15(3):273-7.

13. Borg J, Holm L, Cassidy JD, Peloso PM, Carroll LJ, von Holst H, et al. Diagnostic procedures in mild traumatic brain injury: results of the WHO collaborating centre task force on mild traumatic brain injury. J Rehabil Med. 2004 Feb;(43 Suppl): 61-75.

14. Kennedy JE, Lumpkin RJ, Grissom JR. A survey of mild traumatic brain injury treatment in the emergency room and primary care medical clinics. Mil Med. 2006 Jun;171(6):516-21.

15. Borg J, Holm L, Peloso PM, Cassidy JD, Carroll LJ, von Holst H, et al. Non-surgical intervention and cost for mild traumatic brain injury: results of the WHO collaborating centre task force on mild traumatic brain injury. J Rehabil Med Suppl. 2004 Feb;36 (43): $76-83$

16. Comper P, Bisschop SM, Carnide N, Tricco A. A systematic review of treatments for mild traumatic brain injury. Brain Inj. 2005 Oct;19(11):863-80.

17. Carroll LJ, Cassidy JD, Holm L, Kraus J, Coronado VG, WHO Collaborating Centre Task Force on Mild Traumatic Brain Injury. Methodological issues and research recommendations for mild traumatic brain injury: The WHO collaborating centre task force on mild traumatic brain injury. [see comment]. J Rehabil Med. 2004 Feb; 43 Suppl:113-25.

18. Kraus JF, McArthur DL, Silberman TA. Epidemiology of mild brain injury. Semin Neurol. 1994 Mar;14(1):1-7.

19. Pickett W, Ardern C, Brison RJ. A population-based study of potential brain injuries requiring emergency care. Can Med Assoc J. 2001;165:288-92.

20. Schootman M, Fuortes LJ. Ambulatory care for traumatic brain injuries in the US, 1995-1997. Brain Inj. 2000 Apr;14(4):373-81.

21. Sosin DM, Sniezek JE, Thurman DJ. Incidence of mild and moderate brain injury in the United States, 1991. Brain Inj. 1996 Jan;10(1):47-54.

22. Jaakkimainen L, Upshur R, Klein-Geltink J, Leong A, Maaten S, Schultz S, et al. Primary care in Ontario: ICES atlas. Toronto: Institute for Clinical Evaluative Sciences; 2006.

23. 2006 census [homepage on the Internet]. Available from: http://www12.statcan.ca/.

24. ICD-9-CM: International Classification of Diseases, 9th revision, Clinical Modification. 5th Ed Salt Lake City, Utah: Medicode; 1997.

25. Norman GR. Biostatistics: the bare essentials. 2nd ed. Streiner DL, editor. Hamilton: B.C. Decker; 2000.

26. Landis JR, Koch GG. The measurement of observer agreement for categorical data. Biometrics. 1977 Mar;33(1):159-74.

27. Ontario Physician Human Resources Data Centre [homepage on the Internet]. [cited December 2007]. Available from: https://www.ophrdc.org/Home.aspx.

28. Ghaffar O, McCullagh S, Ouchterlony D, Feinstein A. Randomized treatment trial in mild traumatic brain injury. J Psychosom Res. 2006; 61(2);153-60.

29. Ponsford J. Rehabilitation interventions after mild head injury. Curr Opin Neuro. 2005; 18:692-7.

30. Russell WR. Cerebral involvement in head injury. Brain. 1932; 55: 549-603.

31. Hustey FM, Meldon SW. The prevalence and documentation of impaired mental status in elderly emergency department patients. Ann Emerg Med. 2002; Mar 39:248-53.

32. Servadei F, Teasdale G, Merry G. Neurotraumatology Committee of the World Federation of Neurosurgical Societies. Defining acute mild head injury in adults: a proposal based on prognostic factors, diagnosis, and management. J Neurotrauma. 2001 Jul;18 (7):657-64.

33. McCrory P, Johnston K, Meeuwisse W, Aubry M, Cantu R, Dvorak $\mathrm{J}$, et al. Summary and agreement Statement of the Second International Symposium on Concussion in Sport. Br J Sports Med. 2005; 39(4):196-204.

34. Klauber MR, Barrett-Conner E, Marshall LF, Bowers SA. The epidemiology of head injury: a prospective study of an entire community-San Deigo, California, 1978. Am J Epidemiol. 1981; 113:500-9.

35. Tate RL, McDonald S, Lulham JM. Incidence of hospital-treated traumatic brain injury in an Australian community. Aust N Z J Public Health. 1998 Jun;22(4):419-23.

36. Anderson DW, Kalsbeek WD, Hartwell TD. The national head and spinal cord injury survey: design and methodology. J Neurosurg. 1980 Nov;Suppl:S11-8.

37. Bazarian JJ, Veazie P, Mookerjee S, Lerner EB. Accuracy of mild traumatic brain injury case ascertainment using ICD-9 codes. Acad Emerg Med. 2006 Jan;13(1):31-8. 